\title{
Life Assessment Prognostic Modelling for Multi-layered Coating Systems using Multi-disciplinary approach
}

\author{
Jawwad Latif $^{1 *}$, Zulfiqar Ahmad Khan ${ }^{1}$, Mian Hammad Nazir ${ }^{1}$, Keith Stokes ${ }^{2}$, Joseph Plummer ${ }^{3}$ \\ ${ }^{1}$ Bournemouth University, NanoCorr, Energy and Modelling (NCEM), Faculty of Science \& \\ Technology \\ ${ }^{2}$ University of Southampton, National Centre for Advanced Tribology at Southampton (nCATS) \\ Faculty of Engineering and the Environment, Southampton SO17 1BJ
}

${ }^{3}$ Physical Sciences Division, Defence Science \& Technology Laboratory DSTL, Ministry of Defence, Porton Down, Salisbury, SP4 0JQ

*Corresponding author email: jlatif@bournemouth.ac.uk

Postal address: Poole House, Fern Barrow, Poole BH12 5BB, UK

\begin{abstract}
The multi-disciplinary approach has been adopted to model the formation and propagation of blistering effect for evaluation of useful coating life in the multi-layered coating-substrate system. Prognostic model of de-bonding driving force has been formulated as a function of material science, solid mechanics and fracture mechanics properties to estimate critical, safe and fail conditions of the coatingsubstrate system. The blister growth velocity rate is also included in the developed model to estimate the blister propagation as a function of diffusion-induced stress and residual stress. The proposed prognostic modelling for the formation and propagation of blistering effect are combined to form an assessment model for evaluation of useful coating life of the multi-layered coating-substrate system and validated through experimental observation.
\end{abstract}

Keywords: Multi-layered coating; Delamination; Blistering; Modelling

Nomenclature

$\begin{array}{ll}\sigma_{d_{s}} & \text { Diffusion induced stress of substrate material } \\ \sigma_{d_{c i}} & \text { Diffusion induced stress for } i^{\text {th }} \text { coating material } \\ \sigma_{r_{c i}} & \text { Residual stress for } i^{\text {th }} \text { coating material } \\ \sigma_{r_{s}} & \text { Residual stress of substrate material } \\ \overline{V_{p k}} & \text { Partial molar volume } \\ c^{\prime}{ }_{k} & \text { Concentration gradient } \\ \mathrm{s} & \text { Thickness of substrate } \\ \varepsilon_{u_{d}} & \text { Uniform bending strain due to diffusion-induced stress } \\ \varepsilon_{u_{r}} & \text { Uniform bending strain due to residual stress } \\ \rho_{d} & \text { Bending curvature due to diffusion-induced stress } \\ \rho_{r} & \text { Bending curvature due to residual induced stress }\end{array}$




\begin{tabular}{|cl|}
\hline$\mu_{k}^{Q}$ & Chemical potential for isotropic material \\
$r$ & Radius of blister \\
$E_{i}$ & Elastic modulus of $i^{\text {th }}$ coating material \\
$h_{i}$ & Thickness of $i^{\text {th }}$ layer of coating \\
$v_{i}$ & Poisson's ratio of $i^{\text {th }}$ material \\
$\sigma_{c r}$ & Critical stress of single layer coating \\
$\sigma_{c r^{\prime}}$ & Critical stress of multi-layered coating \\
$G_{O}$ & Resultant strain energy release rate \\
$T_{t h}$ & Total thickness of coating \\
$\sigma_{T}$ & Total unbuckled stress \\
$\cap$ & De-bonding index \\
$\Gamma_{\mathrm{IC}}$ & Interface toughness \\
$j$ & Mode mixity ratio \\
$\lambda$ & Roughness parameter \\
$\psi$ & Mode adjustment term \\
$F_{c r}$ & Critical de-bonding driving force \\
$F$ & De-bonding driving force \\
$M_{T h}$ & Threshold bending moment \\
$M_{i n i}$ & Initiation bending moment \\
$\mathrm{a}$ & Blister diameter \\
& Blister amplitude \\
\hline &
\end{tabular}

\section{Introduction}

Thin film coatings cover a wide range of applications in the field of optics, chemistry, mechanics, magnetics, electricity, automobiles, civil infrastructure, aerospace and medical field; computers hard disks, video and audio tapes are also coated with thin films. In optics, coatings are applied for antireflection and decorative purposes. Coatings act as a diffusion barrier to preserve the materials from environmental factors which cause oxidation reactions that lead to coating and structural failure. In aircraft and automobiles, structures are protected from corrosion under severe environmental conditions by applying an appropriate coating system. Factors that lead to coating failure are mainly; environmental factors, inappropriate sample preparation, incorrect selection of coating, service environment, poor application, improper drying of coating times and mechanical damage. Coating failures cause such immense amount of financial loss that the cost of repairing defected areas commonly exceeds the initial cost of coating. The maintenance cost can be reduced by identifying the coating failure at the earliest possible stage ${ }^{1-3}$. 
The factors which are responsible for coating failures affect the materialistic and mechanical properties of coating which results in different forms of coating failures such as blistering (Osmotic and nonOsmotic), microcracks, edge delamination, ridge cracks, bubbling, abrasion and adhesion failure. Buckling in the multi-layered coating has been investigated for initiation of buckling through experimental analysis and a prognostic model and growth rate has been formulated to find the debonding driving force to predict critical, fail and safe states. The change in temperature, thermal expansion mismatch between coating and substrate and in-plane compressive stress are key factors in the formation of blisters. Researchers have incorporated multiple parameters to model failure mechanism of coated systems. Mathematical solutions for elastic deformation of multi-layered beams due to residual stresses and external bending have been formulated by Hu $\mathrm{tal}^{4}$. Stress in multi-layered coating system has been investigated and a closed form solution is proposed in ${ }^{5}$. Loss of adhesion and variation in electrical properties in multi-layered films due to the effect of stresses has also caused major concerns for semiconductor industry ${ }^{6}$. Solutions to analyse deformation in multi-layered coating system affected by stresses, in-plane loading and external bending are presented in ${ }^{7}$ and these relations can be further utilised to determine the stiffness, thickness, thermal expansion coefficient or thermal gradient.

Comprehensive experimental and theoretical studies have been conducted by researchers to investigate the improvement in mechanical properties of multi-layered coating by evaluation of various types of material compositions, varying the thickness of coating layers and evaluating the mechanical, thermal and magnetic properties via buckling test, nanoindentation test, scratching test, tensile test, corrosion and high-temperature test ${ }^{8-12}$. It has been found that oxidation has an inverse relationship to the number of interfaces in the multi-layered coating which makes it more resistive towards corrosion ${ }^{13}$. Osmotic and non-Osmotic phenomena between substrate and coating play a major role in the formation and growth of blisters. The presence of salt particles in water acting as cations drives the osmotic pressure with hydroxide acting as anions which appear through an electrochemical reaction due to microstructural defects in materials ${ }^{14}$. Several models in mathematical form have been developed to observe the phenomena of blisters formation and propagation. Bressers et al. presented a discussion premature cracking of oxidation-resistant coatings using fracture mechanisms and mechanics concepts ${ }^{15}$. An investigation of blistering effect in Ti/Al multi-layered coating through a modified experimental blister test is given by Galindo et al. ${ }^{16}$. Blister propagates in a pressure sensitive tape on a steel substrate before approaching to maximum pressure. Dry cycles are responsible for degradation in tape adhesion and support in making a path for transport of species ${ }^{17}$. Strain energy density factor by using mix mode conditions with stress intensity factors to estimate the durability of the coating was derived ${ }^{18}$. Prawoto et al found that the strain energy density factor could be further combined with fracture mechanics to observe the growth of blister as crack propagation and diffusion of corrosive species concept to estimate the critical and safe condition of a coating system ${ }^{19}$.

The NanoCorr, Energy and Modelling Group at Bournemouth University has developed several models to compute the de-bonding driving force and corrosion current rate as a function of residual and diffusion-induced stresses by using material science, solid mechanics and fracture mechanics concepts. The mobility of corrosive products induces diffusion stress that can also alter the residual stress from $15 \mathrm{MPa}$ to $5 \mathrm{MPa}$ compression. The proliferation of blistering does not depend on the thickness ratio of coating and substrate but adhesion between coating and substrate can be improved by increasing the ratio of elastic modulus of coating and substrate material ${ }^{20}$. Normalised stress, at the substrate interface, depends on the chemical potential of diffusive elements and blister formation takes place when it exceeds the critical stress level. Interfacial toughness is a function of elastic mismatch parameters and angular deflection which varies mix mode parameter between $-\pi / 2$ and $\pi / 2$. It has been shown that mobility and concentration of cations plays a vital role in coating de-bonding from substrate ${ }^{21}$. A prognostic model for life assessment of exhaust mufflers has been developed by incorporating electrochemical reactions at the surface of the metal and dropwise condensation process ${ }^{22}$. In the presence of residual stress, a coefficient of thermal expansion (CTE) mismatch and negative change in 
temperature induces tensile stress which expands the micro-cracks already present in coating before the corrosive species approach saturation level ${ }^{23}$. Nucleation and Propagation of blisters in the cracks of the coating have also been modelled by coupling the effects of residual and diffusion-induced stresses ${ }^{24}$. Previous investigation of coating failures, i.e. blistering, delamination, micro-cracks and corrosion damage measurement in real time has been reported ${ }^{25-48}$.

\section{Experimental observation}

The S275 material has been used as substrate in experimental analysis; it is a structural steel grade which has been designed with specific chemical compositions and mechanical properties formulated for particular applications. S275 has a Young modulus of 210 $\mathrm{GPa}$ and coefficient of thermal expansion as $12 \times 10^{-6} /{ }^{\circ} \mathrm{C}$. Composition and properties of S275 are shown in Table $1^{49}$. Samples were conditioned before coating with the same grit size to produce roughness on the substrate interface. The roughness of each sample is measured through an optical interferometer. Samples were coated with primers along with alkyd topcoat as shown in fig.1. Properties of alkyd coatings have been investigated by Armelin et al. in detail ${ }^{50}$. Red oxide primer coating has Young's modulus of $6.14 \mathrm{GPa}$ and the coefficient of thermal expansion is $21.6 \times 10^{-6} /{ }^{\circ} \mathrm{C}{ }^{24}$. Sample 1 has mono-layer coat, sample 2 has bi-layer coating and sample 3 has tri-layer coating respectively. Total thickness of each sample was measured

Figure 1 Coating Layers

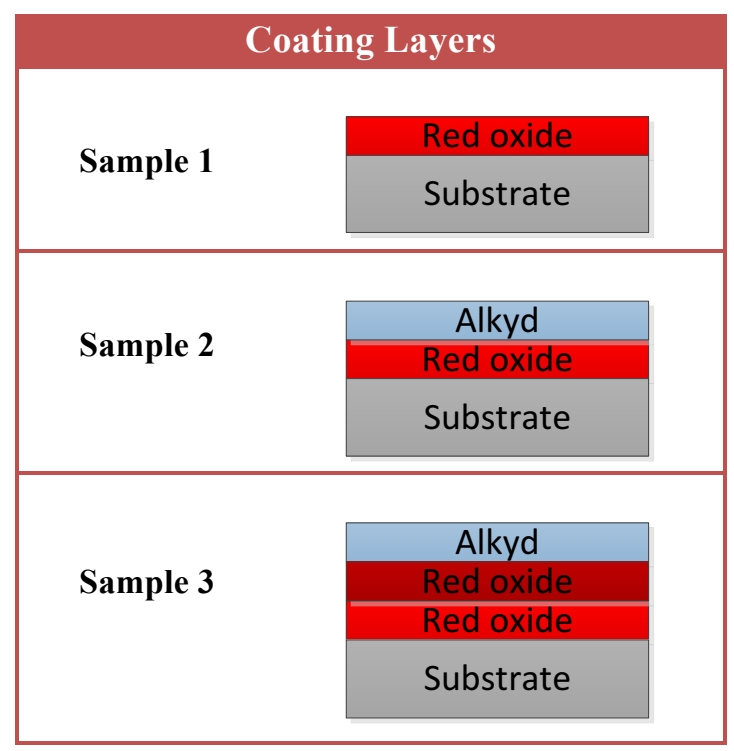

by using Scanning Electron Microscopy. Thickness and average roughness of each sample before and after coating is given in Table 2. Samples were degreased with acetone before exposing them to corrosive aqueous solution, a solution of $5 \mathrm{M}$ $\mathrm{NaCl}$ in distilled water. The thickness of coatings was measured through Scanning Electron Microscopy as shown in Fig 2. Layers are labelled with yellow lines to differentiate between them. It was observed that more application defects were measured as the number of coatings are applied on the samples increases. After corrosion testing, surface profiles of all samples have been investigated through 3D Optical Surface Profilometer. Multiple blisters have been identified on the surface of samples due to the osmotic process, mismatch of thermal coefficient, diffusion induced stresses and residuals stresses. The blisters with maximum amplitude from each sample are considered for comparison and are shown in fig.3. Sample 1 with mono-layered coating has largest number and size of blisters observed. The maximum blister amplitude for the mono-layered coated sample was $26.03 \mu \mathrm{m}$ while bi-layered coated sample had maximum blister amplitude of $24.8 \mu \mathrm{m}$. The amplitude of the largest blister in the tri-layered coated sample is $16.64 \mu \mathrm{m}$ which is comparatively small to mono-layered and bi-layered coated sample.

Table 1 Steel S275 composition [25]

\begin{tabular}{|c|c|c|c|c|c|}
\hline \multicolumn{7}{|c|}{ Composition and Properties of S275 } \\
\hline Elements & $\mathrm{C} \%$ & $\mathrm{Mn} \%$ & $\mathrm{P} \%$ & $\mathrm{~S} \%$ & $\mathrm{Si} \%$ \\
\hline Quantity & $0.25 \mathrm{max}$ & $1.60 \mathrm{max}$ & $0.04 \mathrm{max}$ & $0.05 \mathrm{max}$ & $0.05 \mathrm{max}$ \\
\hline $\begin{array}{c}\text { Yield Strength at nominal } \\
\text { thickness 16mm }\end{array}$ & $275 \mathrm{~N} / \mathrm{mm}^{2}$ & $\begin{array}{c}\text { Tensile Strength at thickness } \\
\text { between 3mm and 16mm }\end{array}$ & $370-530 \mathrm{MPa}$ \\
\hline
\end{tabular}


Table 2 Substrate roughness and coating thickness

\begin{tabular}{|c|c|c|c|}
\hline \multirow{2}{*}{ Sample No. } & \multicolumn{2}{|c|}{ Average roughness (Ra) } & \multirow{2}{*}{ Coating Thickness mm } \\
\cline { 2 - 3 } & Pre-coating & Post-coating & 0.035 \\
\hline $\mathbf{1}$ & 0.328 & 1.63 & 0.083 \\
\hline $\mathbf{2}$ & 0.488 & 1.72 & 0.125 \\
\hline $\mathbf{3}$ & 0.384 & 1.53 & \\
\hline
\end{tabular}



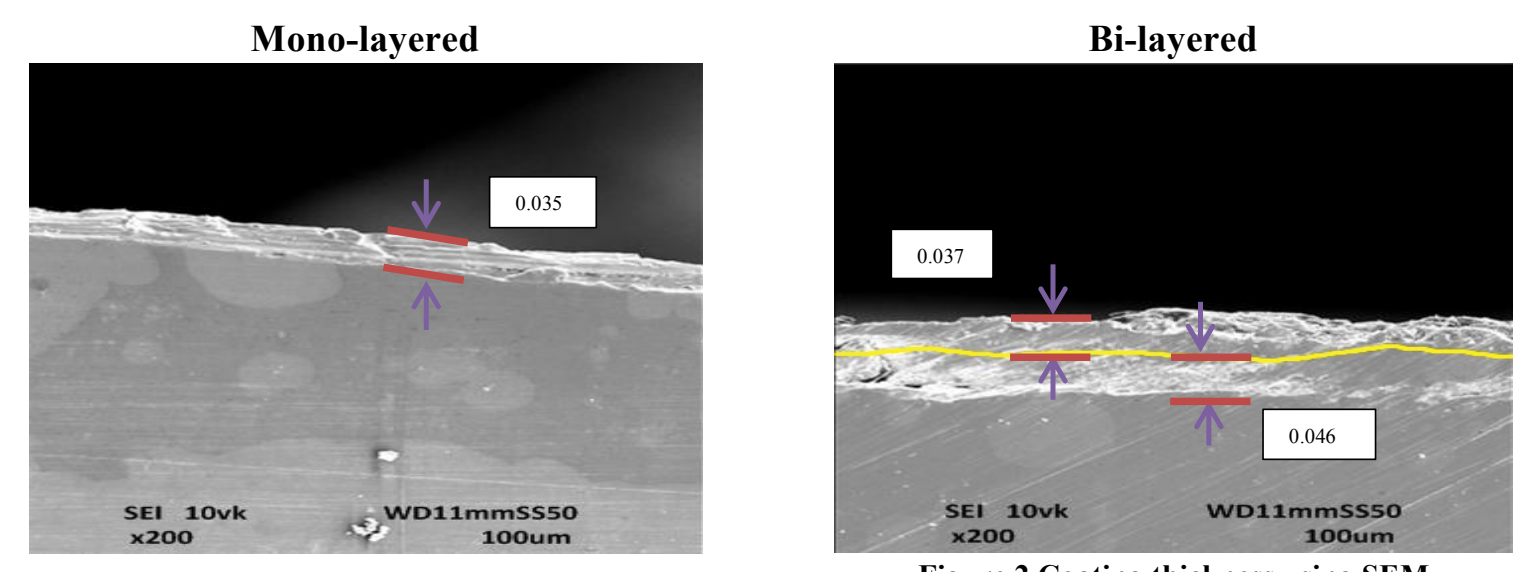

Tri-layered

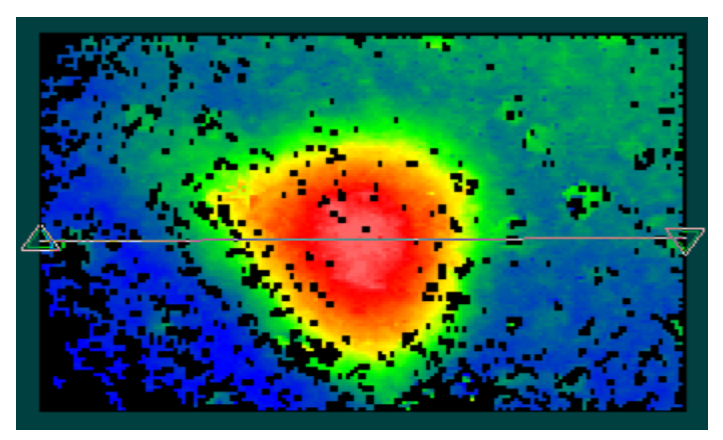

\section{Figure 2 Coating thickness using SEM}
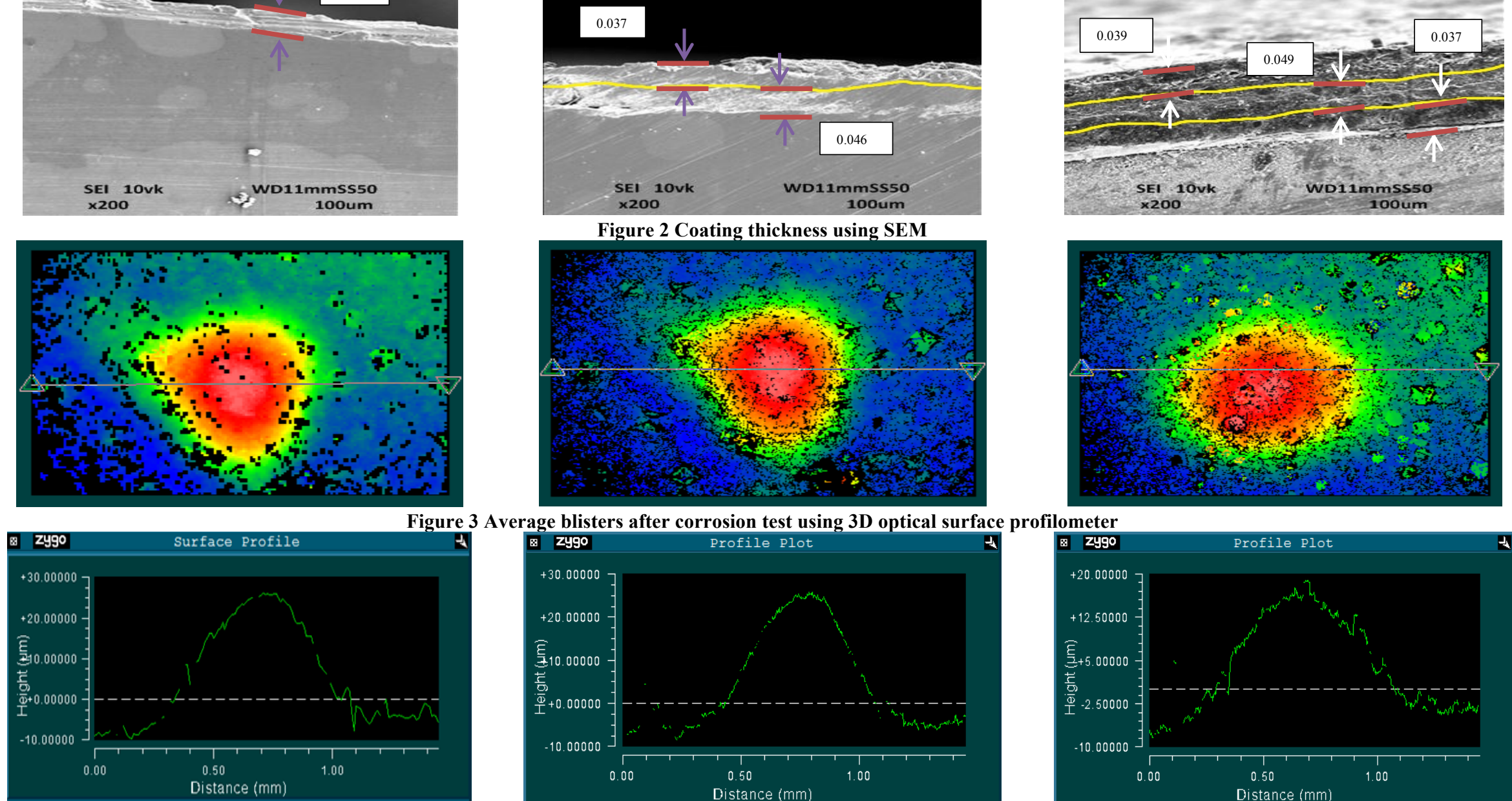

igure 3 Average blisters after corrosion test using 3D optical surface profilometer
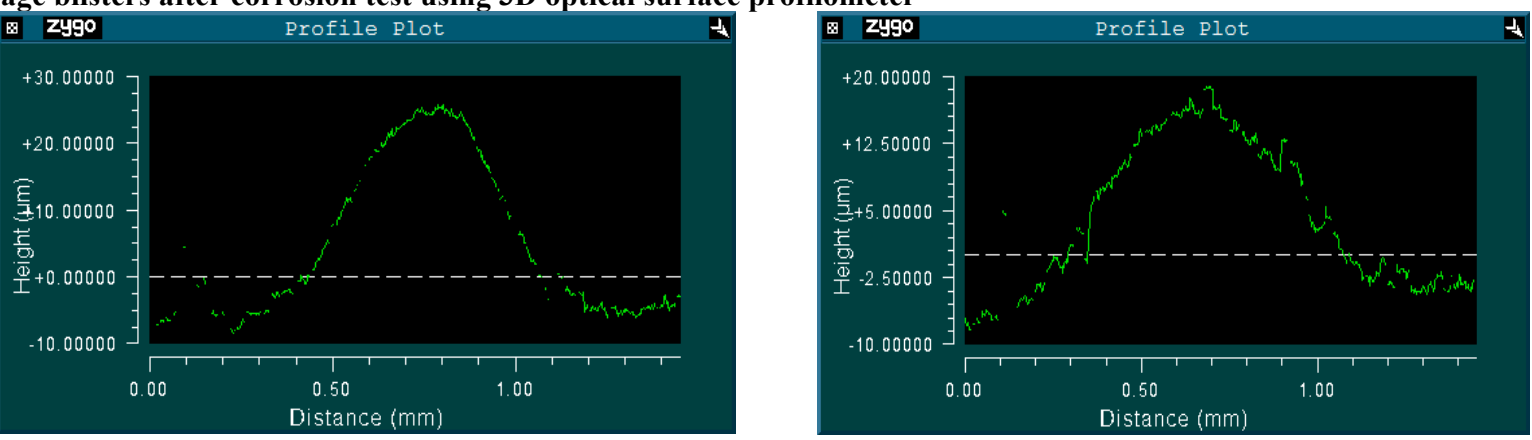

Figure 4 Blister amplitude using 3D optical surface profilometer

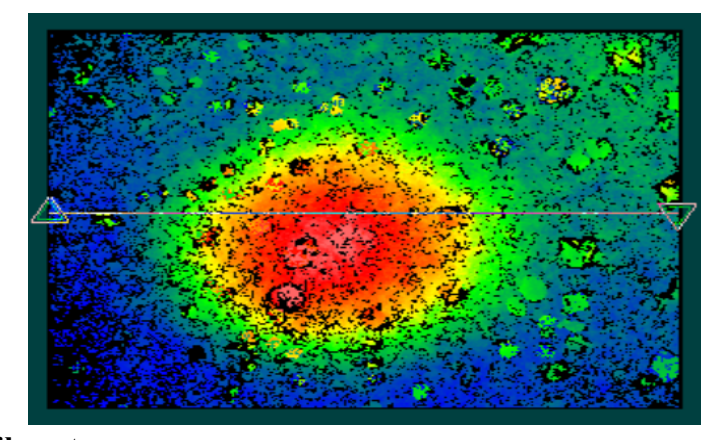




\section{Modelling of multi-layered coating}

The aim of current research is to develop a prognostic model for failure prediction and the reliability assessment of multi-layered coating on metals by using a multi-disciplinary approach as shown in Fig.5. Residual stress depends on the change in temperature and coefficient of thermal expansion while corrosive species generate diffusion-induced stress which causes delamination. Bending models are derived for residual and diffusion-induced stresses. Material science and solid mechanics concepts are then combined to compute the change in concentration of corrosive species with respect to time, incorporating the effects of stresses in the multi-layered system. The energy release rate lies under the fracture mechanics concept defined as the de-bonding driving force which is released when the coating is separated from the substrate. The relationship for the de-bonding driving force as a function of residual and diffusion-induced stresses is derived to compute critical, safe and fail states of multilayered coatings.

Deformation in film coating systems depends on changes in temperature, the coefficient of thermal expansion (CTE) mismatch and Young's modulus of material and substrate. Delamination of multilayers due to the effect of residual stresses has previously been formulated ${ }^{51}$. The product of thermal expansion coefficient $\alpha$ and change in temperature $\Delta \mathrm{T}$ dictates thermal stress-strain. The relation between thermal stress-strain and normal stress in cantilever beam is $\sigma=E(\varepsilon-\alpha \Delta T)$ where $\varepsilon$ strain and $\mathrm{E}$ represents Young's modulus. Temperature gradient can be taken equal to concentration gradient and thermal expansion $\alpha$ to partial molar volume $\overline{V_{p k}} 52$.

$$
\sigma_{d}=E\left(\varepsilon-\frac{1}{3} c^{\prime}{ }_{k} \overline{V_{p k}}\right)
$$

Deformation of multi-layers caused by residual stress has been modelled ${ }^{51}$ by using solid mechanics concept. These models can be used in conjunction with the diffusion model to assess the life of multilayered coatings. The relation for the normal stress of a substrate and multi-layered coating incorporating ${ }^{52}$ concept and can be given as;

$$
\begin{gathered}
\sigma_{d_{s}}=E_{s}\left(\varepsilon-\frac{1}{3} c_{k_{s}} \overline{V_{p k_{s}}}\right) \\
\sigma_{d_{c i}}=E_{c i}\left(\varepsilon-\frac{1}{3} c_{k_{c i}} \overline{V_{p k_{c l}}}\right) \quad \text { where } i=1 \ldots . n \text { layers }
\end{gathered}
$$

The diffusion induced strain is a composition of uniform bending and bending component as $\varepsilon=\varepsilon_{u}+$ $\varepsilon_{b}$. If the thickness of substrate is given as s, thickness of the coating is $\mathrm{h}$ and curvature is represented by $\rho$ then the relation of uniform strain $\varepsilon_{u}$ is given as, $\varepsilon_{u}=x-t_{b} / \rho$ for $(-s \leq x \leq h)$. When the coating remains intact with the substrate, $x=t_{b}$ then bending strain is zero $\left(\varepsilon_{b}=0\right)$ and strain in a system becomes equal to uniform strain as $\varepsilon=\varepsilon_{u}$. To simplify calculations, it is assumed that $c_{k_{j}}^{\prime}=$ $\frac{1}{3} c_{k_{j}}$ and $\overline{V_{p k_{j}}}=\frac{1}{3}{\overline{V_{p k_{s}}}}^{\prime}$ where, $j=s, c_{i}$ for the rest of calculations. The average stress distribution of multi-layered coatings, using eq. 2(a) and 2(b) can be given as;

$$
\int_{-s}^{0} E_{s}\left(\varepsilon_{u_{d}}-\frac{1}{3} c_{k_{s}}^{\prime} \overline{V_{p k_{s}}}\right) d x_{s}+\sum_{i=1}^{n} \int_{h_{i-1}}^{h_{i}} E_{c i}\left(\varepsilon_{u_{d}}-\frac{1}{3} c_{k_{c i}}^{\prime} \overline{V_{p k_{c l}}}\right) d x_{c i}=0
$$

The solution of eq. 3 gives uniform bending strain $\varepsilon_{u}$ for multi-layered coating when the coating is intact with the substrate. 


$$
\begin{aligned}
& \varepsilon_{u_{d}}=\frac{\left(E_{S} S c_{k_{s}}^{\prime} \overline{V_{p k_{s}}}+\sum_{i=1}^{n} E_{i} t_{i} c_{k_{i}}^{\prime} \overline{V_{p k_{l}}}\right)}{E_{S} s+\sum_{i=1}^{n} E_{i} t_{i}} \quad \text { where } i \\
& =1 \ldots . n \text { layers }
\end{aligned}
$$

Using first-order approximation, uniform bending strain can write as,

$$
\begin{aligned}
\varepsilon_{u_{d}}=\overline{V_{p k_{s}}} c_{k_{s}}^{\prime} & +\sum_{i=1}^{n} \frac{E_{i} t_{i}\left(c_{k_{i}}^{\prime} \overline{V_{p k_{l}}}-c_{k_{s}}^{\prime} \overline{V_{p k_{s}}}\right)}{E_{s} s} \quad \text { where } i \\
& =1 \ldots . n \text { layers }
\end{aligned}
$$

The applied moment is in equilibrium with the summation of bending moment with respect to the bending axis $\left(x=t_{b}\right)$. If $\mathrm{M}$ is the applied moment per unit width of multi-layered system then,

$$
\int_{-s}^{0} \sigma_{d_{s}}\left(x-t_{b}\right) d x+\sum_{i=1}^{n} \int_{h_{i-1}}^{h_{i}} \sigma_{d_{c_{i}}}\left(x-t_{b}\right) d x=M
$$

By incorporating eq. 2(a), eq. 2(b), eq.4 in eq.6 gives,

$$
\int_{-s}^{0} E_{s}\left(\varepsilon_{u}-\frac{1}{3} c_{k_{s}}^{\prime} \overline{V_{p k_{s}}}\right)\left(x-t_{b}\right) d x_{s}+\sum_{i=1}^{n} \int_{h_{i-1}}^{h_{i}} E_{c i}\left(\varepsilon_{u}-\frac{1}{3} c_{k_{c i}}^{\prime} \overline{V_{p k_{c l}}}\right)\left(x-t_{b}\right) d x_{c i}=M
$$

The solution of above equation gives us a relation for bending equation. Bending curvature is represented as $\rho_{d}$.

$$
\frac{1}{\rho_{d}}=\frac{3\left[E_{s}\left(\varepsilon_{u}-c_{k_{s}}^{\prime} \overline{V_{p k_{s}}}\right) s^{2}-\sum_{i=1}^{n} E_{i} t_{i}\left(\varepsilon_{u}-c_{k_{i}}^{\prime} \overline{V_{p k_{i}}}\right)\left(2 h_{i-1}+t_{i}\right)\right]+6 M}{E_{S} s^{2}\left(2 s+3 t_{b}\right)+\sum_{i=1}^{n} E_{i} t_{i}\left[6 h_{i-1}^{2}+6 h_{i-1} t_{i}+2 t_{i}^{2}-3 t_{b}\left(2 h_{i-1}+t_{i}\right)\right]}
$$

Assuming the resultant force due to uniform stress components for multi-layers is zero, Eq. 6 can be written as;

$$
\int_{-s}^{0} \sigma_{d_{s}}\left(x-t_{b}\right) d x+\sum_{i=1}^{n} \int_{h_{i-1}}^{h_{i}} \sigma_{d_{c_{i}}}\left(x-t_{b}\right) d x=0
$$

By incorporating eq. 2(a), eq. 2(b), eq.4 in eq.9 gives,

$$
\begin{aligned}
\int_{-s}^{0} E_{s}\left(\varepsilon_{u_{d}}-\frac{1}{3}\right. & \left.c_{k_{s}}^{\prime} \overline{V_{p k_{s}}}\right)\left(x-t_{b}\right) d x_{s} \\
& +\sum_{i=1}^{n} \int_{h_{i-1}}^{h_{i}} E_{c i}\left(\varepsilon_{u_{d}}-\frac{1}{3} c_{k_{c i}}^{\prime} \overline{V_{p k_{c l}}}\right)\left(x-t_{b}\right) d x_{c i}=0
\end{aligned}
$$

The thickness of the multi-layered coating is less than the thickness of substrate which simplifies the solution. The bending moment $\mathrm{M}$ has been ignored to study residual stress in the multi-layered system ${ }^{51}$. Using First order approximation and ignoring applied moment the relationships of bending curvature can be given as;

$$
\frac{1}{\rho_{d}}=6 \sum_{i=1}^{n} \frac{E_{i} t_{i}\left(c_{k_{i}}^{\prime} \overline{V_{p k_{l}}}-c_{k_{s}}^{\prime} \overline{V_{p k_{s}}}\right)}{E_{s} s^{2}}
$$

Bending curvature for each coating can be formulated as;

$$
\frac{1}{\rho_{d_{i}}}=6 \frac{E_{i} t_{i}\left(c_{k_{i}}^{\prime} \overline{V_{p k_{l}}}-c_{k_{s}}^{\prime} \overline{V_{p k_{s}}}\right)}{E_{S} s^{2}}
$$


Thus Eq.11 (a) can be written as;

$$
\frac{1}{\rho_{d}}=\sum_{i=1}^{n} \rho_{d_{i}}
$$

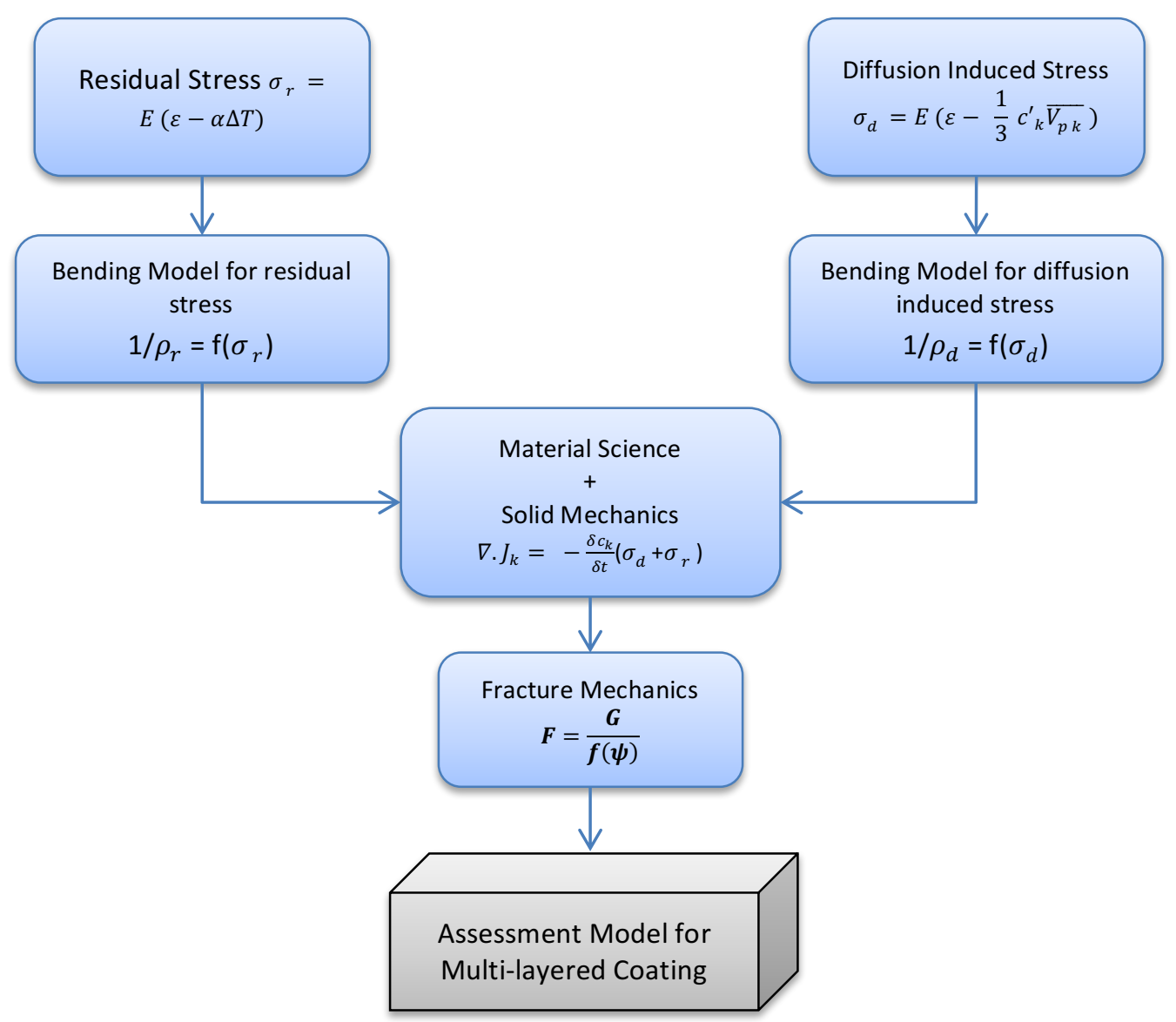

Figure 5 Multi-disciplinary modelling approach

The above bending curvature relationship is similar to the relation derived by Hseush et al. ${ }^{51}$, but the thermal expansion and temperature gradient are taken analogues to partial molar volume and change in concentrations of species. This analogous relationship has been used to determine the effect of diffusion-induced stress in Li-Ion battery electrode particles ${ }^{52}$. The relation for deformation of multilayered coating system due to residual stress has been derived by ${ }^{51}$. Uniform bending strain due to residual stress is given as;

$$
\varepsilon_{u_{r}}=\alpha_{s} \Delta T+\sum_{i=1}^{n} \frac{E_{i} t_{i}\left(\alpha_{i}-\alpha_{s}\right) \Delta T}{E_{s} s} \quad \text { where } i=1 \ldots . n \text { layers }
$$

Bending curvature due to residual stress is formulated as,

$$
\frac{1}{\rho_{r}}=6 \sum_{i=1}^{n} \frac{E_{i} t_{i}\left(\alpha_{i}-\alpha_{s}\right) \Delta T}{E_{S} s^{2}}
$$




\subsection{Integration of diffusion and bending model}

Fick's laws of diffusion describe diffusion and were derived as provided in ${ }^{53}$. According to Fick's first law, diffusion flux is proportional to the change in chemical potential. According to Li et al ${ }^{54}$, chemical potential for isotropic materials can be defined as;

$$
\mu_{k}^{Q}=\mu_{k}^{s}+R T \ln \left(c_{k}\right)-\overline{V_{p k}} \sigma_{d}
$$

Where $J_{k}$ represents diffusion flux, $D_{k}$ is diffusion coefficient, $c_{k}$ represents concentration of the species, $\nabla \mu_{k}$ represents gradient of chemical potential and $\mathrm{R}$ is the molar gas constant. A change in chemical potential defines a change in the thermodynamics state of system. the $\mu_{k}^{s}$ is chemical potential in standard state, $\mu_{k}^{Q}$ represents chemical potential corresponding to the stressed state of coating. $\overline{V_{p k}}$ represents partial molal volume of component $\mathrm{k}$. $\sigma_{d}$ is diffusion induced stress due to mobility of corrosive species, $\mathrm{R}$ is the molar gas constant and $\mathrm{T}$ is temperature. Fick's second law, which defines change in the concentration of species with respect to time, can be utilised to compute transport of corrosive species in coating material ${ }^{24}$.

$$
\frac{\delta c_{k}}{\delta t}=D_{k} \nabla^{2} c_{k}-\frac{\overline{V_{p k}} D_{k}}{R T} \nabla c_{k} \nabla\left(\sigma_{d}+\sigma_{r}\right)-\frac{\overline{V_{p k}} D_{k}}{R T} c_{k} \nabla^{2}\left(\sigma_{d}+\sigma_{r}\right)
$$

By incorporating the above relations in the diffusion model, relation for change in concentration of species in the multi-layered system can be derived. The diffusion model for substrate and multi-layered coating is given as;

$$
\frac{\delta c_{k_{s}}}{\delta t}=D_{k_{s}} \nabla^{2} c_{k_{s}}-\frac{\overline{V_{p k_{s}}} D_{k_{s}}}{R T} \nabla c_{k_{s}} \nabla\left(\sigma_{r_{s}}+\sigma_{d_{s}}\right)-\frac{\overline{V_{p k_{s}}} D_{k_{s}}}{R T} c_{k_{s}} \nabla^{2}\left(\sigma_{r_{s}}+\sigma_{d_{s}}\right)
$$

Model for change in concentration of species due to residual and diffusion-induced stress has been derived and experimentally validated in ${ }^{23}$.

$$
\frac{\delta c_{k_{c_{i}}}}{\delta t}=\left\{\left(D_{k_{c_{i}}}+\frac{D_{k_{c_{i}}} E_{c_{i}} V_{p_{k_{c_{i}}}}^{2}}{9 R T} c_{k_{c_{i}}}\right) \frac{\partial^{2} c_{k_{c}}}{\partial^{2} x}+\frac{D_{k_{c_{i}}} E_{c_{i}} V_{k_{c_{i}}}^{2}}{9 R T}\left(\frac{\delta c_{k_{c_{i}}}}{\delta t}\right)^{2}-\frac{D_{k_{c}} E_{c_{i}} V_{k_{c}}^{2}}{9 R T} \frac{\delta c_{k_{c_{i}}}}{\delta t}\left(\frac{1}{\rho_{d_{i}}}+\frac{1}{\rho_{r_{i}}}\right)\right\}
$$

Terms can be written as $\frac{E_{c_{i}}}{\rho_{d_{i}}}=\frac{\partial \sigma_{d_{c_{i}}}}{\partial t} \quad \frac{E_{c_{i}}}{\rho_{r_{i}}}=\frac{\partial \sigma_{r_{c_{i}}}}{\partial x}$,

$$
\begin{gathered}
\sigma_{T}=\sigma_{d}^{\prime}+\sigma_{r}^{\prime}=\frac{\partial \sigma_{d_{c_{i}}}}{\partial t}+\frac{\partial \sigma_{r_{c_{i}}}}{\partial x} \\
\frac{\partial \sigma_{d_{c_{i}}}}{\partial t}+\frac{\partial \sigma_{r_{c_{i}}}}{\partial x}=\frac{\left(D_{k_{c_{i}}}+\frac{D_{k_{c_{i}}} E_{c_{i}} V_{p_{k_{c_{i}}}}^{2}}{9 R T} c_{k_{c_{i}}}\right) \frac{\partial^{2} c_{k_{c}}}{\partial^{2} x}+\frac{D_{k_{c_{i}}} E_{c_{i}} V_{p_{k_{c_{i}}}}^{2}}{9 R T}\left(\frac{\delta c_{k_{c_{i}}}}{\delta t}\right)^{2}}{\frac{D_{k_{c}} V_{p_{c_{i}}}^{2} \frac{\delta c_{k_{c_{i}}}}{\delta t}}{9 R T}}
\end{gathered}
$$

\subsection{Fracture mechanics concept}

Propagation and initiation of delamination can be investigated under the umbrella of fracture mechanics. The de-bonding driving force which is a function of substrate and coating material properties, roughness and thickness define detachment of coating from the substrate ${ }^{55}$. When stress reaches a certain value, 
which is defined as critical stress, then buckling initiates and its propagation depends on the toughness of the material. Critical stress as defined in ${ }^{56}$ is given as;

$$
\sigma_{c r}=1.2235 \frac{E}{\left(1-v^{2}\right)}\left(\frac{T_{t h}}{r}\right)^{2}
$$

Where, $T_{t h}$ is the total thickness of coating, $\mathrm{r}$ is the radius of blister induced by buckling between coating and substrate, E is Young's modulus and $v$ is the Poisson's ratio of coating material.

Examination of buckling delamination in multi-layered coatings by using fracture mechanics concept was performed in ${ }^{55-57}$. The relations given by ${ }^{57}$ for delamination of multi-layered thermal barrier coating are applicable for other multi-layered coating systems. The critical value of stress in multilayered system at which buckling initiates is given as;

$$
\sigma_{c r^{\prime}}=\left(\frac{\pi}{r}\right)^{2} \frac{1}{3} \sum_{i=1}^{n} \frac{E_{i}}{\left(1-v_{i}^{2}\right)}\left[\left(x_{i+1}-t_{b}\right)^{3}-\left(x_{i}-t_{b}\right)^{3}\right]
$$

$\sigma_{c r^{\prime}}$ represents critical stress level for multilayered coating, $\mathrm{r}$ is the radius of blisters induced by buckling between coating and substrate, $x_{i+1}$ and $x_{i}$ are the top and bottom locations of $i^{\text {th }}$ coating layer.

The strain energy release rate defines de-bonding driving force which is required to generate buckling between coating and substrate. High fracture toughness means the de-bonding force will experience more resistance. Strain energy in multi-layered coating system depends on mechanical properties of the coating materials. Energy stored in the multi-layered system that can be released by plane strain without any buckling or bending is given as ${ }^{55}$ :

$$
G_{0}=\frac{\sigma_{c}^{2}}{2} \sum_{i=1}^{n} \frac{\left(1-v_{i}^{2}\right)}{E_{i}} t_{i}
$$

Diffusion induced stress in the multi-layered model is incorporated in the proposed prognostic model to find the value of strain energy release rate. The relation of strain energy release rate in multi-layered system is given as;

$$
G=\frac{M^{2}}{2 B}+\frac{N^{2}}{2 S}
$$

$G$ represents the strain energy release rate which can be defined as a de-bonding driving force. $M$ is the bending moment, $N$ is the resultant pre-buckling stress. $B$ and $S$ are bending stiffness and stretching stiffness of multi-layered coating system respectively. Relations for $B$ and $S$ are given in Appendix A.

Solving eq.21 by incorporating B and S relations gives the following equation to calculate strain energy release rate as a function of stresses. Eq.23 seems similar to the equation derived in ${ }^{58}$ for single layered coating system. The solution of eq. 23 is given in Appendix A.

$$
G^{\prime}=\frac{3}{2} \sum_{i=1}^{n} \frac{\left(1-v_{i}{ }^{2}\right)}{E_{i}\left(x_{i+1}-t_{p}\right)^{3}-\left(x_{i+1}-t_{p}\right)^{3}} M^{2}\left[1+\frac{1}{4}\left({\sqrt{\left.\sigma_{T} / \sigma_{0^{\prime}}-1\right)}}^{2}\right)\right]
$$

Propagation depends on mode adjusted de-bonding driving force. The de-bonding driving force, which defines the detachment of coating from the substrate, is a function of strain energy release rate and mode mix function ${ }^{58}$. 


$$
\begin{gathered}
\mathrm{F}=\frac{G^{\prime}}{\mathrm{j}} \\
\mathrm{j}=\sec ^{2}\left[\left(1-\frac{\Gamma_{\mathrm{IC}}}{E_{c} \lambda}\right) \psi\right]
\end{gathered}
$$

Where $\lambda$ is the ratio between square of average roughness amplitude $\left(R_{a v}\right)$ and average roughness wavelength $\left(L_{a v}\right)$ as $\lambda=R_{a v}{ }^{2} / L_{a v}$. $\psi$ represents mode adjustment term. Dimensionless mode mix function can be used to adjust mode dependent strain energy release rate for isotropic materials attached to each other, mode mixing relation can be given as;

$$
\begin{gathered}
\tan \psi=\frac{\mathrm{K}_{2}}{\mathrm{~K}_{1}}=\frac{\sqrt{12}+\left(T_{t h} \Delta N / \Delta M\right) \tan \omega}{-\sqrt{12} \tan \omega+\left(T_{t h} \Delta N / \Delta M\right) \tan \omega} \\
\frac{T_{t h} \Delta N}{\Delta M}=\left(\sqrt{\frac{3\left(\sigma_{c_{T}}-\sigma_{0^{\prime}}\right)}{B\left(\frac{\pi}{r}\right)^{2}}}\right)
\end{gathered}
$$

The de-bonding driving force can be written as a function of toughness, stresses, bending moment, total coating thickness, elastic modulus, Poisson ratio and interface roughness of the substrate. The following relation is similar to relation derived and experimentally validated ${ }^{58}$ for single layered coating optimisation.

$$
F=\frac{\left.\frac{3}{2} \sum_{i=1}^{n} \frac{\left(1-v_{i}{ }^{2}\right)}{E_{i}\left(x_{i+1}-t_{p}\right)^{3}-\left(x_{i+1}-t_{p}\right)^{3}} M^{2}\left[1+\frac{1}{4}(\sqrt{n-1})^{2}\right)\right]}{1+\tan \left(\left(1-\frac{\Gamma_{\mathrm{IC}}}{E_{c} \lambda}\right) \frac{\sqrt{12}+\left(T_{t h} \Delta N / \Delta M\right) \tan \omega}{-\sqrt{12} \tan \omega+\left(T_{t h} \Delta N / \Delta M\right)}\right)^{2}}
$$

Where $\mathrm{n}$ is the de-bonding index. From the above relation critical, safe and fail conditions for isotropic coating layers can be found. De-bonding force is dependent on the ratio of resultant stress and critical stress which defines the threshold level for coating failure. When, $\cap<1$, the coating is in safe condition because stress generated has not exceeded the critical stress and blistering has not initiated. $\cap=1$ defines critical threshold level at which blistering effect starts. When $\cap>1$, the coating lies in the fail state which means blistering effect has been initiated. Optimised values for isotropic multi-layered coating system can be computed from the above relation. To find the threshold level, $n=1$ the above equation reduces to following eq.28 (b) which can be used to find critical values of multi-layered isotropic coatings.

$$
F_{c r}=\frac{\frac{3}{2} \sum_{i=1}^{n} \frac{\left(1-v_{i}{ }^{2}\right)}{E_{i}\left(x_{i+1}-t_{p}\right)^{3}-\left(x_{i+1}-t_{p}\right)^{3}} M^{2}}{1+\tan \left(\left(1-\frac{\Gamma_{\mathrm{IC}}}{E_{c} \lambda}\right) \frac{1}{-\tan \omega}\right)^{2}}
$$

\subsection{Blister growth velocity model}

Once the blister has formed, the moment at the verge of blister establishes and causes the formation of cathodic reaction products to accelerate the diffusion process to inflate the blister. The growth rate of blister can be predicted by taking coating as a cantilever beam loaded by bending moment at the edge. 
The total bending moment as a function of stress, coating thickness and amplitude of blister is given by the following relation;

$$
M_{0}=T_{t h} w \sigma_{T}
$$

Where, $T_{t h}$ is coating thickness, $w$ is amplitude of blister and $\sigma$ is stress formed by the diffusion process of corrosive environment and the defects which were formed during the manufacturing processes. The threshold bending moment is given in the following eq. 30. If the value of bending moment is below the threshold value calculated from the following relation and then the blister will not continue to grow 59 .

$$
M_{T h}=0.73 \sqrt{\sum_{i=1}^{n} \frac{E_{i}}{\left(1-v_{i}^{2}\right)}} \sqrt{a \sigma_{T} T_{t h}{ }^{3}}
$$

Where, $E_{i}$ is the modulus of elasticity and $v_{i}$ is the Poisson's ratio of coating material. After the formation of blister, it grows with a velocity that depends on coating properties, temperature, stress induced and the size of blister. The relation for threshold velocity below which the blister will not continue can be calculated as;

$$
V_{\text {min }}=1.83\left(\frac{\sigma_{f}}{a}\right)^{1.25}\left[\frac{D_{b} \delta_{\mathrm{b}} \Omega}{k T}\right]\left[\sum_{i=1}^{n} \frac{E_{i}}{\left(1-v_{i}^{2}\right)} \frac{T_{t h}{ }^{3}}{12}\right]^{-0.25}
$$

Where, $\mathrm{D}_{\mathrm{b}} \delta_{\mathrm{b}}$ is the interfacial diffusivity and $\Omega$ represents volume of the diffusing species. The dimensionless relation for blister growth velocity can be given as;

$$
v=\left[m+\sqrt{m^{2}-1}\right]^{2.5}
$$

The above relation is applicable for $v \geq 1$ and $m \geq 1$, where $v=\frac{V}{V_{\min }}$ is dimensionless velocity and $m=$ $\frac{M_{0}}{M_{T h}}$ is dimensionless moment at blister crack tip respectively. The relation for critical bending moment to predict the blistering initiation process has been derived by Martin et al. ${ }^{60}$ and can be given as:

$$
M_{i n i}=3 \frac{\sum_{i=1}^{n} E_{i} T_{t h}^{3} w}{a^{2}}
$$

According to the above relation, $M_{i n i}$ is a function of blister diameter $a$ and amplitude $w$. After the formation of blister following conditions can be utilised to estimate whether the blister will grow or stop growing. If the value estimated through eq. 30 is greater than the value estimated through eq. 33 then blister will grow after initiation and in opposite scenario blister will not grow, which can be summarised as:

$$
\begin{array}{cc}
\text { If } M_{T h}<M_{i n i} & \text { If } M_{T h}>M_{\text {ini }} \\
\text { Blister }=\text { grow } & \text { Blister } \neq \text { grow }
\end{array}
$$




\section{Coatings life assessment model}

Atmospheric pollutants are a major source of corrosion, and the diffusion of these corrosive species plays a significant role in coating failure mechanism. The corrosive species present at a coating defect starts diffusing into delamination region and forms an electrochemical cell which drives the cathodic delamination process ${ }^{61}$. Research findings have shown that blisters form due to electrochemical process and growth of a blister depend on the bending moment which induces at the edge of the blister. In early research, cathodic blistering mechanisms have been modelled by applying the concept of semi-double cantilever beam theory. In past several years, researchers have adopted a multidisciplinary approach to model the transportation of corrosion products and blister growth phenomena under the umbrella of material science, thermodynamics and fracture mechanics.

Several models have previously been proposed to explain the process of cathodic delamination. Wan et al ${ }^{62}$ formulated elastic energy release rate for blister formation and growth as a function of blister height and pressure. The relationship proposed by Bresser et al ${ }^{15}$ models elastic energy release rate as a function of blister amplitude, pressure and thickness of the coating. Jahensen and Volonsky et al ${ }^{63}$ have also developed identical kind of relations. Later on, the relation between energy release rate as a function of stiffness, pressure, blister amplitude, blister radius and coating thickness was developed by Kappes et al. ${ }^{64}$. Prawoto et al. ${ }^{18}$ have combined the material science concepts with fracture mechanics and also modelled blister mechanism by including J-integral concept. Stratmann et al. ${ }^{65}$ investigated cathodic deamination process through various experimental techniques and developed a corrosion model. Later on, an extensive model was proposed by Allahar et al. ${ }^{66}$ based on the experimental observation that rate of diffusion of corrosive species and formation of $\mathrm{OH}$ - ions define the adhesion loss between coating and substrate. Hutchinson ${ }^{55,56,67}$ has done comprehensive work on explaining the blister formation and propagation mechanism using fracture mechanics concepts which are modified by Khan-Nazir ${ }^{21}$ for interfacial toughness and mod mix equations.

The de-bonding driving force as a function of mechanical and chemical characteristics of coating and substrate modelled by Khan-Nazir is further extended for multilayered coated systems and combined with blister velocity growth to propose a coatings useful life assessment model. The model can be utilised to evaluate and compare multiple coatings in terms of adhesion loss and the speed at which a blister will propagate once it has appeared. The model takes material and mechanical parameters of coating and substrate as input. It computes the critical level de-bonding driving force at which blister initiates. After calculating the critical level of de-bonding force, the current value of de-bonding force is being computed and continuously monitored and compared with critical level to predict the formation of a blister. If the current de-bonding force is less than the critical level than a blister has not formed, while a blister appears when de-bonding force surpasses its critical level. The bending moment at blister initiation is taken as the initiation bending moment. The threshold bending moment is computed after blister formation to compare it with initiation bending moment. The conditions for blister growth or stops given in the previous section are evaluated to predict the propagation of blister. If blister continues to grow than its growth velocity can be computed to estimate the rate at which coatings are losing adhesion with the substrate. The model provides a prediction of adhesion loss for multi-layered coatings as well as the failure rate after losing adhesion and can be used to differentiate the performance of coatings useful life and behaviour after falling into a fail state. 


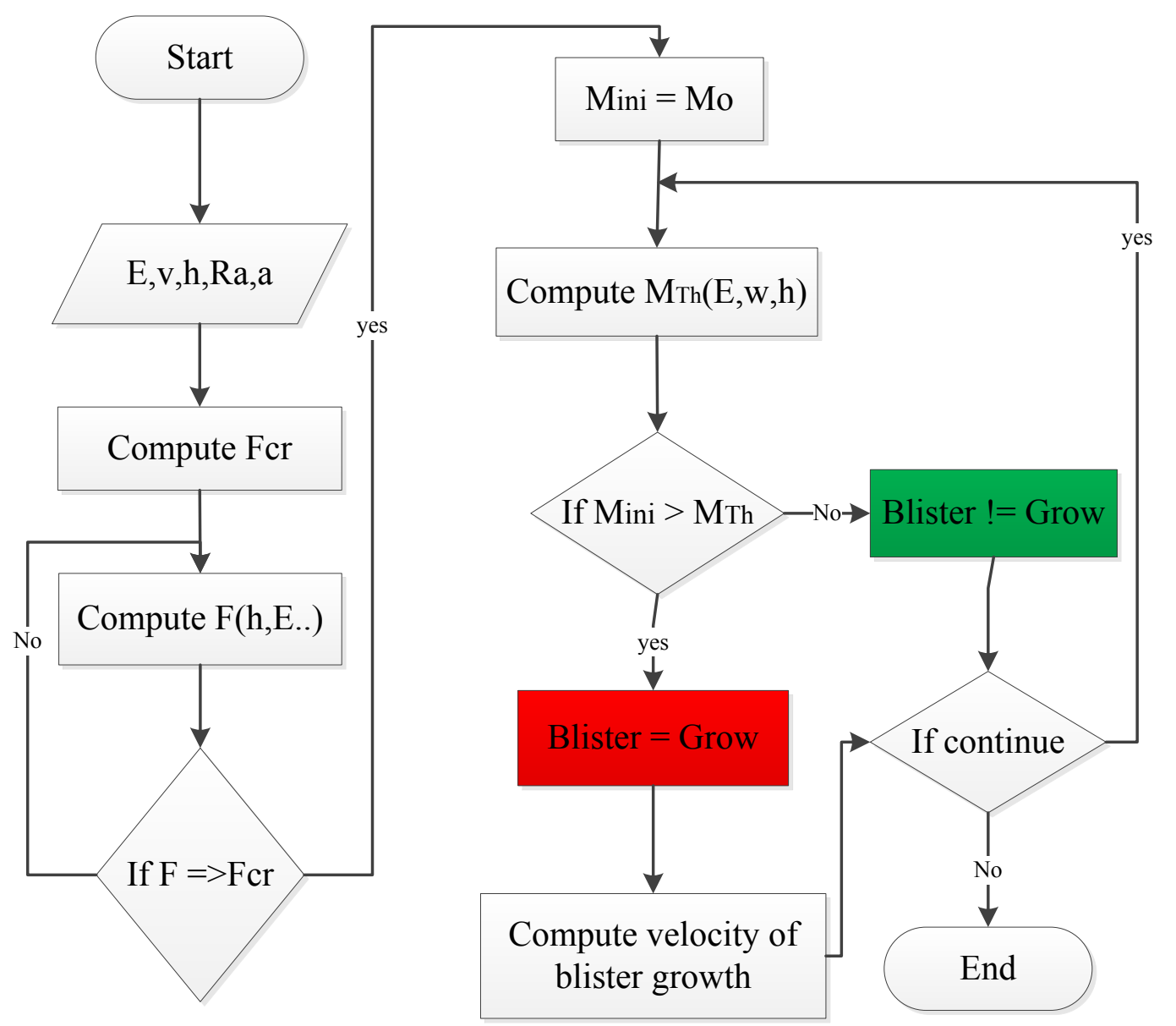

Figure 6 Coating life assessment model

\section{Mathematical model implementation}

Initial boundary conditions are given as:

$$
\begin{array}{cl}
c_{k_{c_{i}}}(x)=c_{k_{s}}=0 & \text { for time } t=0 \\
c_{k_{c_{i}}}(h)=c_{k_{0}} & \text { for time } t>0
\end{array}
$$

All parameters and variables are converted into a dimensionless form for numerical simulation as:

$$
\begin{gathered}
\widetilde{{c_{c_{l}}}}=c_{k_{c_{i}}} / c_{k_{0}} \\
\breve{E}=\frac{2}{3} \sum_{i=1}^{n} \frac{E_{i}}{\left(1-v_{i}^{2}\right) E_{s}} \\
\widetilde{D_{k}}=D_{k_{c_{i}}} / D_{k_{s}}
\end{gathered}
$$




$$
\begin{gathered}
\tilde{A}=\left(\frac{E_{c_{i}} V_{p_{c_{c_{i}}}}^{2}}{R T}\right) c_{k_{0}} \\
\frac{1}{\check{\rho}_{d_{i}}}=\frac{1}{\rho_{d_{i}} c_{k_{0}} V_{p_{k_{0}}}}=6 \sum_{i=1}^{n} \frac{E_{i} t_{i}\left(c_{k_{i}}^{\prime} \overline{V_{p k_{l}}}-c_{k_{s}}^{\prime} \overline{V_{p k_{s}}}\right)}{E_{S} s^{2} c_{k_{0}} V_{p_{k_{0}}}} \\
\frac{1}{\check{\rho}_{r_{i}}}=\frac{1}{\rho_{r_{i}} \alpha_{k_{0}} \Delta T_{k_{0}}}=6 \sum_{i=1}^{n} \frac{E_{i} t_{i}\left(\alpha_{i}-\alpha_{s}\right) \Delta T}{E_{S} s^{2} \alpha_{k_{0}} \Delta T_{k_{0}}} \\
\check{x}=\left(\left(x_{i+1}-t_{p}\right)^{3}-\left(x_{i}-t_{p}\right)^{3}\right) /\left(s+T_{t h}\right)
\end{gathered}
$$

After applying dimensionless parameters and variables eq.28 (a) and eq.28 (b) can be written as:

$$
\begin{gathered}
\widetilde{F}=\frac{(1 / \tilde{E}) \widetilde{M}(1 / \tilde{x})}{1+\tan \left((1-\widetilde{\boldsymbol{B}}) \frac{1}{-\tan \omega}\right)^{2}}\left[1+\frac{1}{4}\left(\sqrt{n-1}^{2}\right)\right] \\
\tilde{F}_{c r}=\frac{(1 / \tilde{E}) \widetilde{M}(1 / \tilde{x})}{1+\tan \left((1-\widetilde{\boldsymbol{B}}) \frac{1}{-\tan \omega}\right)^{2}}
\end{gathered}
$$

For numerical solution the Runge-Kutta method has been utilised to find the de-bonding driving force as a function of change in the stress with the following steps;

a) Input parameters into prognostic model e.g. Poisson's ratio, elastic modulus, thermal coefficients etc.

b) Calculate the critical stress levels and critical de-bonding driving force by using eq.19, eq.20 and 35(b).

c) Apply Runge-Kutta method to update the change in $\sigma_{T}$ by using eq. 18 .

d) Use the updated value obtained in step $\mathrm{c}$ to find the de-bonding driving force by using Eq. 30(a).

e) Compare the value of de-bonding driving force obtained in step 4 to find critical, safe and fail conditions. If $\tilde{F}<\tilde{F}_{c r}$ show coating is in safe condition, $\tilde{F}>\tilde{F}_{c r}$ represents fail condition while $\tilde{F}=\tilde{F}_{c r}$ means coating is in critical condition.

f) Evaluate the convergence criteria for de-bonding driving force by using Eq. 36(c) in Appendix A and repeat the process if it converges.

g) When the coating enters into critical condition the bending moment at that stage is taken as initiation bending moment.

h) Threshold bending moment is computed to find the possibility of blister growth.

i) If initiation bending moment is greater than threshold bending moment then the blister will not grow.

j) If initiation bending moment is less than threshold bending moment then the blister will grow. 
k) The velocity of blister growth can be calculated from Eq. 32 .

\section{Results and discussions}

Buckle driven blistering delamination has been modelled in terms of de-bonding driving force as a function of diffusion induced and residual stresses for multi-layered organic isotropic coatings to predict useful coating life. The proposed model can be utilised to compare and measure the performance of multiple coating materials. By using a multi-layered model, the effect of multiple layers can be incorporated for more reliable prediction of coating failure as most of the substrates in different applications are coated with multiple coats. Experimental and simulation analyses show a very strong agreement. Multiple coating layers reduce the de-bonding driving force, so blister formation takes more time to appear and propagate. Experiments were conducted and the results show the behaviour of blistering initiation and propagation in single and multi-layered coated substrates. The three samples which were subjected to a corrosive environment at $350 \mathrm{~K}$ showed blisters of variable sizes and at different times, depending on the properties. After the surface analysis of samples, the average size of a blister from each sample is selected for observation and analysis. Blister formation in multi-layered coated samples is assumed to be between substrate and coatings while coating layers remain intact.

The blister size distribution is plotted in fig. 7 to show the difference of blister size among samples. The mono-layered coated sample has the lowest strength and it showed the largest number of blisters and the average blister had $25 \mu \mathrm{m}$ amplitude with approximately $7 \mathrm{~mm}$ of diameter. The average blister amplitude of bi-layered coated sample is $23 \mu \mathrm{m}$ with a diameter of $6 \mathrm{~mm}$ between the other two samples that were $23 \mathrm{~mm}$ which was more than expected, which may be the effect of stresses developed within coating during the application. Meanwhile, the average blister that formed on the trilayered coated sample was much smaller than others, with amplitude of approximately $15 \mu \mathrm{m}$ with a diameter of 8 $\mathrm{mm}$. The point of interest is to identify the critical stage at which blister initiates. The blister initiation stages have been shown in fig. 8 which is observed through experimental analysis. The result plotted in fig. 8 shows the relation of blister formation and time. The sample prior to the blistering effect is considered in a safe state while after formation of a blister the sample is considered in the fail state.

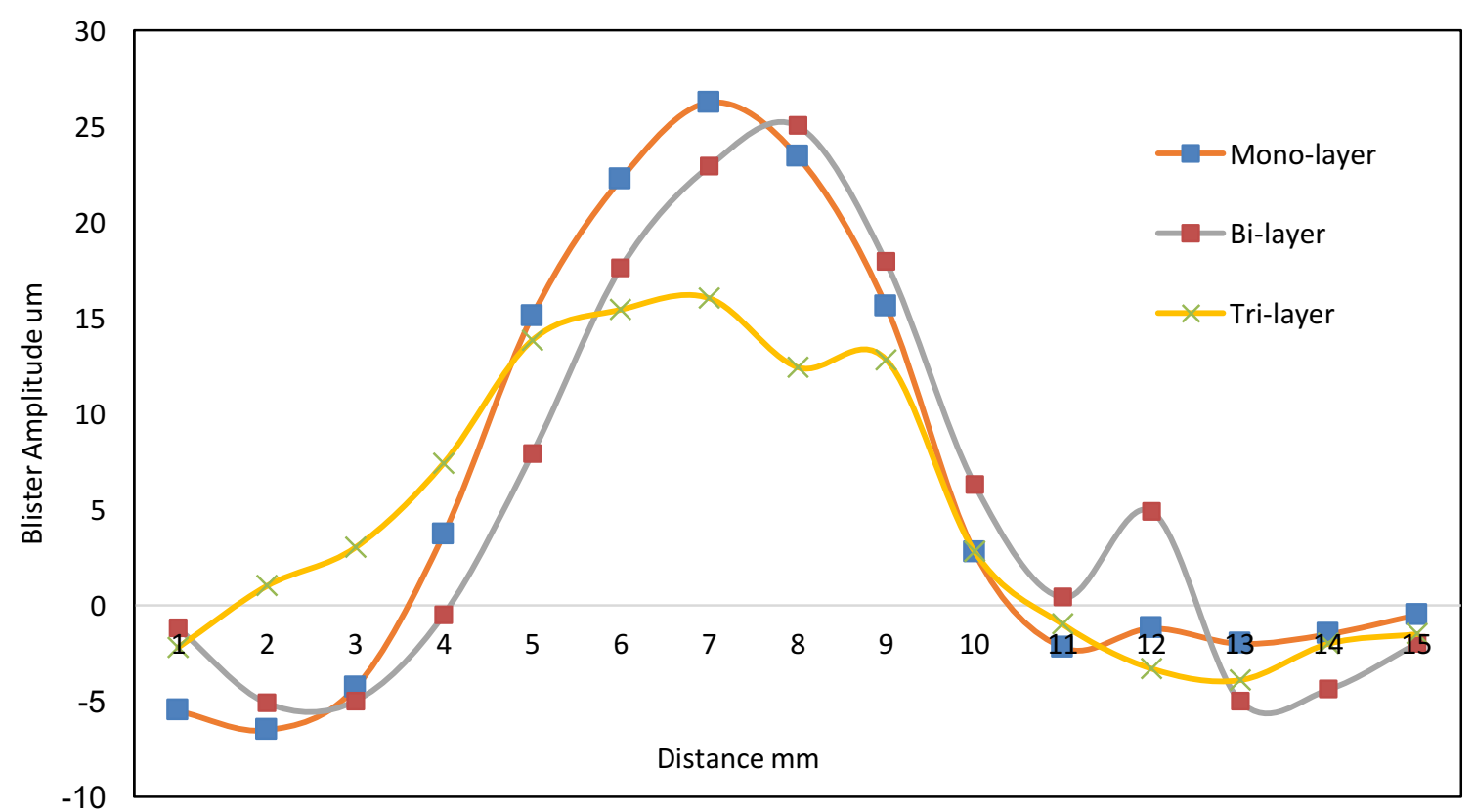

Figure 7 Comparison of average blister size of each sample 


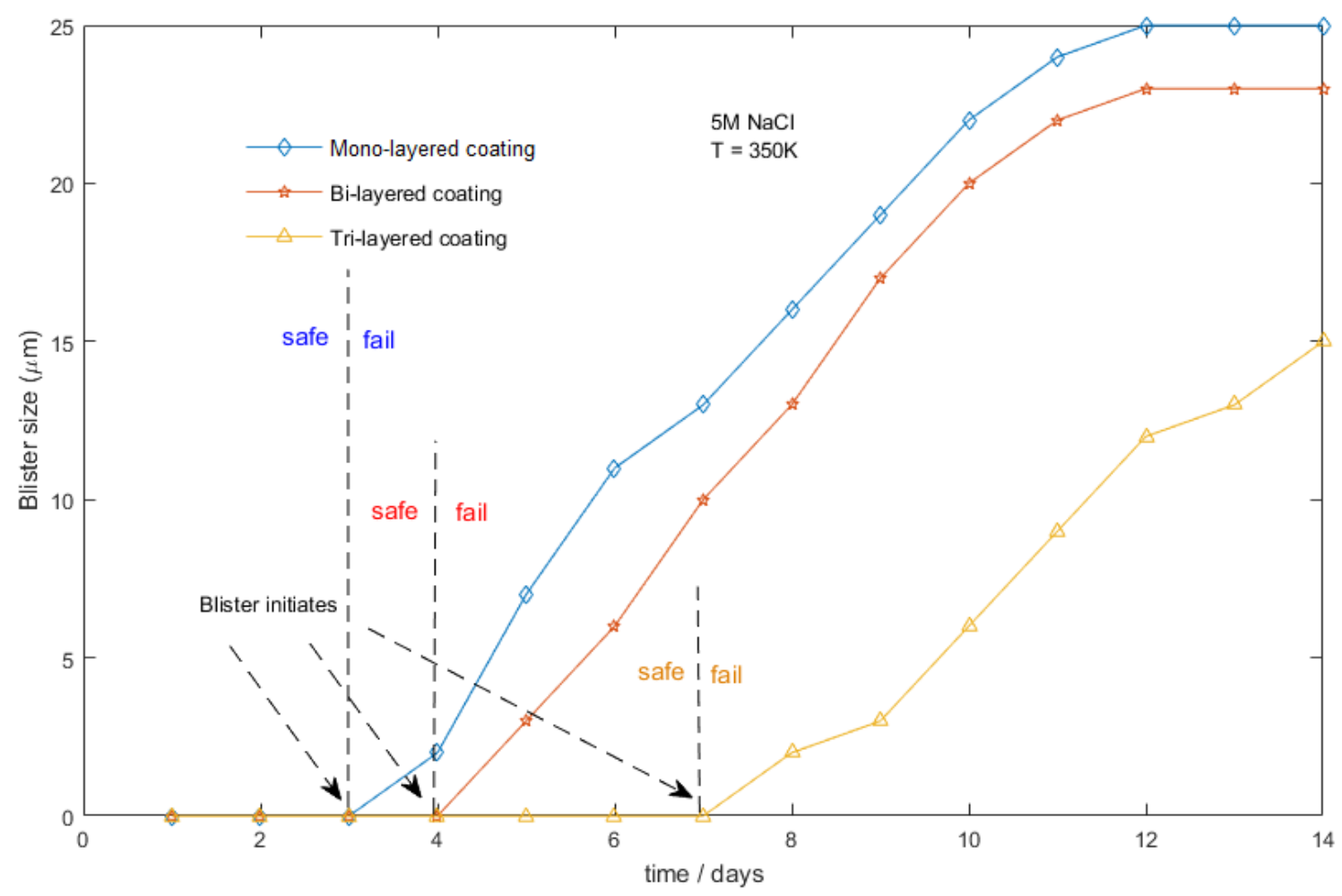

Figure 8 Experimental observation of blisters initiation and propagation

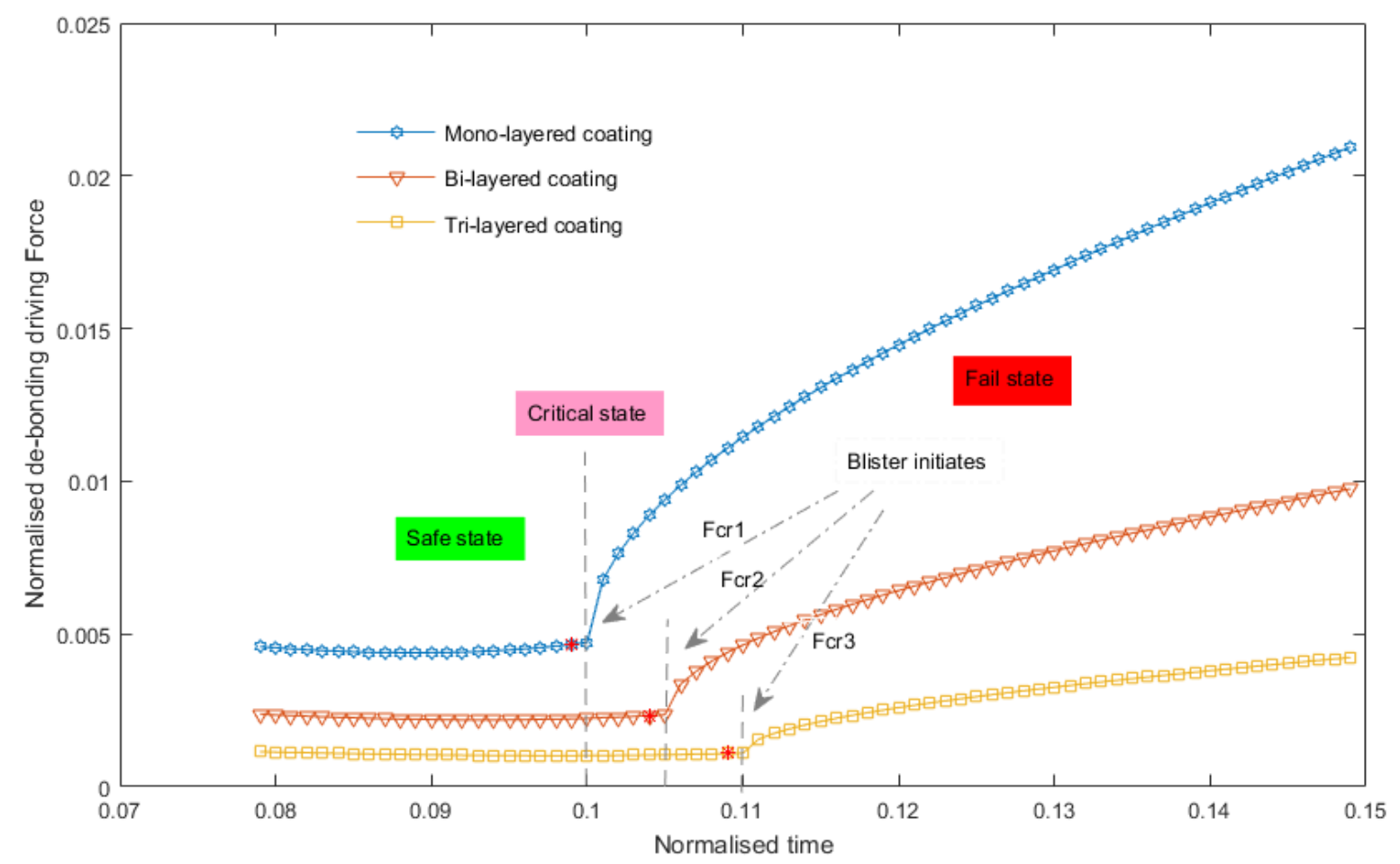

Figure 9 Simulation analysis of safe and fail states of each sample

According to the experimental observation, blisters started forming on the sample after approximately 72 hours. Sample 1 is then considered in the fail state because the de-bonding driving force has surpassed its critical level due to osmosis and non-osmosis factors and coating started deteriorating 
from sample substrate. The time taken by sample 2 to reach its critical level then drop into fail state was approximately after 96 hours under the corrosive environmental conditions. The dual layers of coats have lowered the de-bonding driving force as it took more time than sample 1 to surpass its critical level. Sample 3 had the highest adhesion strength as compared to the rest of the samples, the top coat also assisted in lowering the de-bonding force. The buckling effect took approximately 168 hours to start forming blisters on the sample 3 surface and continued increasing until it gained its maximum amplitude. Simulation results for the mathematical model are shown in fig.9. The de-bonding driving force is the parameter which defines the blister initiation through which safe, critical and fail conditions can be defined. The simulation of the algorithm is described in the mathematical model implementation section. The critical de-bonding driving force is computed initially and the de-bonding force is compared to the critical level to find whether it is lying in safe state or fail state. The relationship between the normalised de-bonding driving force and normalised time is plotted and shows similar behaviour to that observed in the experiments. The model can be used to scale it with real-time to find and predict the duration at which coating would be in their critical and fail condition. According to simulation results, the de-bonding driving force has been reduced by multiple coatings depending on their mechanical and chemical properties. Once a blister has formed, it then propagates at a particular velocity depending on bending moment at the edge of the blister. Hence, the prognostic model is further extended to blister growth velocity. If the conditions of blister growth or stoppage as described in section 3.3 are applied by taking the amplitude and diameter of a blister as $25 \mu \mathrm{m}$ and $7 \mathrm{~mm}$ gives the initiation bending moment large then the threshold bending moment, hence the blister tends to keep growing. The velocity of blister growth depends on elastic modulus and with variable coating thicknesses as shown in fig.10. As shown in fig.10 and fig. 11 the blister growth velocity also depends on properties of the coating materials. The proposed model of coating life assessment can be further investigated and evaluated through experimental and simulation by varying coating materials, by measuring blisters per area of particular coating and the effect of variable multiple coating thicknesses with different mechanical and chemical properties.

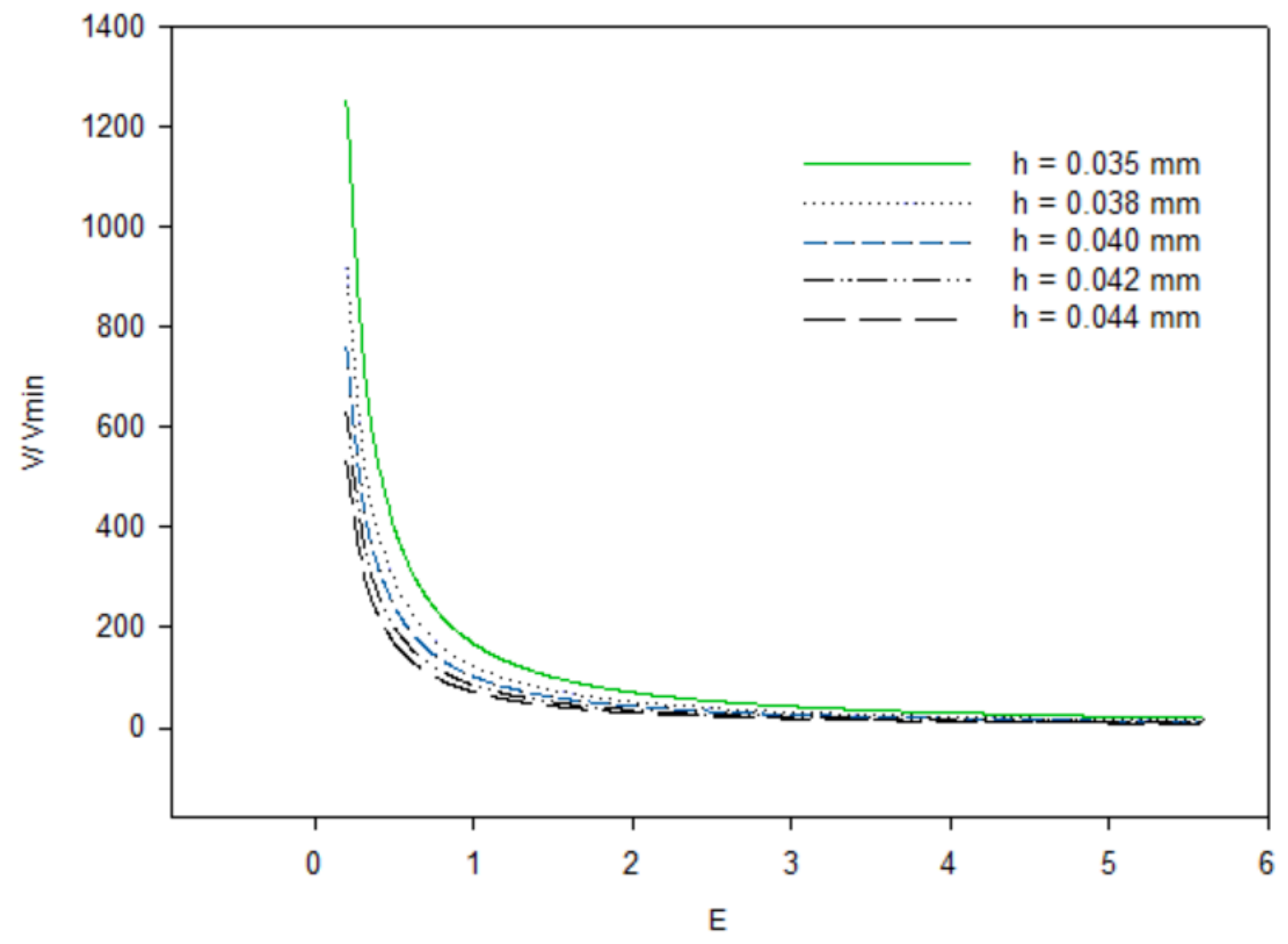

Figure 10 Blister velocity vs. Elastic Modulus 


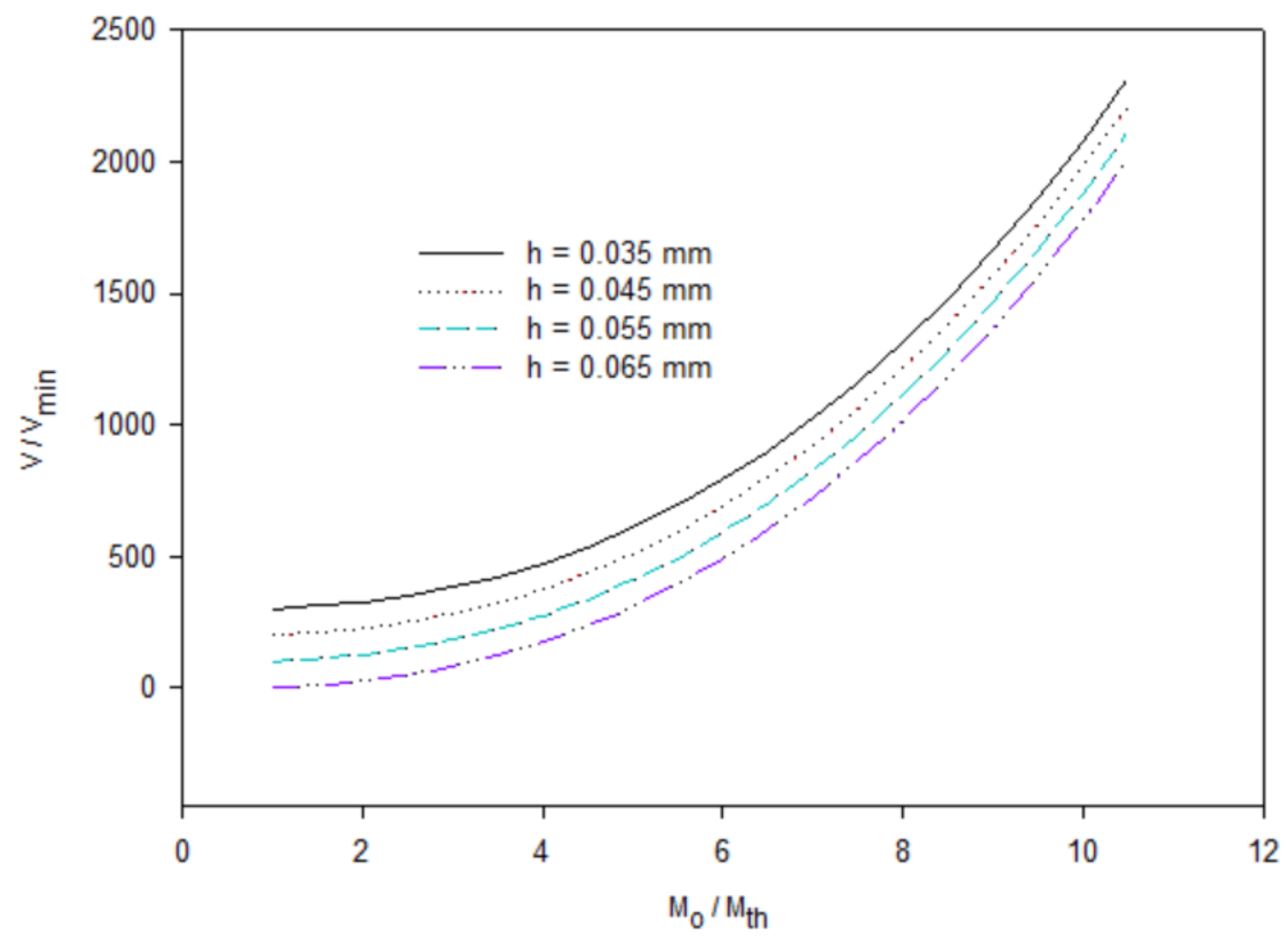

Figure 11 Blister velocity vs. Bending Moment

\section{Conclusion}

The coating failure and corrosion phenomena can cause the whole structure to complete failure which costs human loss, delay in industrial production and huge financial loss. It is very important to design prognostic models by incorporating all the possible parameters in order to evaluate the useful life of protective coatings and schedule the maintenance strategies accordingly. The coating failure mechanism involves various fields of study. Therefore, comprehensive coating life assessment model has been developed using a multi-disciplinary approach to formulate de-bonding driving force. The specimens with protective coatings are tested through experimental analysis to validate the proposed model. The de-bonding driving force predicts three stages as safe, critical and fails state of coating-substrate system operating under corrosive environmental conditions. The formation and propagation of blistering effect were observed during experimental analysis and average blister size is selected from each sample for experimental observation. Further experimental analysis can be carried out to investigate the model in more detail on different types of substrate and coating materials.

\section{Acknowledgements}

This research is jointly funded by Defence Science and Technology Laboratory (DSTL), Ministry of Defence (MoD) UK and Bournemouth University. The authors acknowledge their financial support and in-kind contributions. 


\section{Appendix A}

The relations for bending stiffness (B) and stretching stiffness (s) are given in Eq. 36(a) and Eq. 36(b), when $x=t_{p}$ is at neutral point of axis where coating is attached to substrate, $v$ represents Poisson ratio of coating materials, $t_{i}$ is the thickness of $i t h$ coating layer.

$$
\begin{gathered}
B=\frac{1}{3} \sum_{i=1}^{n} \frac{E_{i}}{\left(1-v_{i}^{2}\right)}\left[\left(x_{i+1}-t_{p}\right)^{3}-\left(x_{i}-t_{p}\right)^{3}\right] \\
S=\sum_{i=1}^{n} \frac{E_{i}}{\left(1-v_{i}^{2}\right)} t_{i} \\
F_{\max }=100 \frac{\left(f^{t+1}-f^{t}\right)}{f^{t}}
\end{gathered}
$$

\section{References}

1. E. Herzberg: 'The annual cost of corrosion for DoD', Proc. Department of Defense Corrosion Conference, 2009.

2. R. W. Revie: 'Corrosion and corrosion control', 2008, John Wiley \& Sons.

3. Y. J. Du, M. Damron, G. Tang, H. Zheng, C.-J. Chu, and J. H. Osborne: 'Inorganic/organic hybrid coatings for aircraft aluminum alloy substrates', Progress in organic coatings, 2001, 41(4), 226-232.

4. N.-H. Zhang and J.-J. Xing: 'An alternative model for elastic bending deformation of multilayered beams', Journal of applied physics, 2006, 100(10), 103519.

5. Y. Hu and W. Huang: 'Elastic and elastic-plastic analysis of multilayer thin films: Closed-form solutions', Journal of applied physics, 2004, 96(8), 4154-4160.

6. H. Liu and S. Murarka: 'Elastic and viscoelastic analysis of stress in thin films', Journal of applied physics, 1992, 72(8), 3458-3463.

7. J. Malzbender: 'Mechanical and thermal stresses in multilayered materials', Journal of applied physics, 2004, 95(4), 1780-1782.

8. N. Moody, S. Venkataraman, J. Nelson, W. Worobey, and W. Gerberich: 'Interface Roughness Effects on Adhesion of Ta 2 N Films', MRS Proceedings, 1993, Cambridge Univ Press, 337.

9. O. Sarikaya: 'Effect of some parameters on microstructure and hardness of alumina coatings prepared by the air plasma spraying process', Surface and Coatings Technology, 2005, 190(2), 388-393.

10. L. Yagmur: 'Effect of microstructure on internal friction and Young's modulus of aged $\mathrm{Cu}-\mathrm{Be}$ alloy', Materials Science and Engineering: A, 2009, 523(1), 65-69.

11. P. Fauchais and A. Vardelle: 'Thermal sprayed coatings used against corrosion and corrosive wear', 2012, INTECH Open Access Publisher.

12. G. T. Chirima, K. M. Zied, N. Ravirala, K. L. Alderson, and A. Alderson: 'Numerical and analytical modelling of multi-layer adhesive-film interface systems', physica status solidi (b), 2009, 246(9), 2072-2082.

13. M. Nordin, M. Herranen, and S. Hogmark: 'Influence of lamellae thickness on the corrosion behaviour of multilayered PVD TiN/CrN coatings', Thin Solid Films, 1999, 348(1), 202-209.

14. J. M. Pommersheim, T. Nguyen, and K. Hartzfeld: 'Prediction of blistering in coating systems', ACS Symposium Series, 1998, American Chemical Society, 137-150.

15. J. Bressers, S. Peteves, and M. Steen: 'Coatings for hot section gas turbine components', European Structural Integrity Society, 2000, 26, 115-134.

16. R. E. Galindo, A. Van Veen, J. Evans, H. Schut, and J. T. M. De Hosson: 'A modified blister test to study the adhesion of thin coatings based on local helium ion implantation', Thin Solid Films, 2005, 471(1), 170-176. 
17. A. Gent and L. Lewandowski: 'Blow-off pressures for adhering layers', Journal of Applied Polymer Science, 1987, 33(5), 1567-1577.

18. Y. Prawoto and B. Dillon: 'Failure analysis and life assessment of coating: the use of mixed mode stress intensity factors in coating and other surface engineering life assessment', Journal of failure analysis and prevention, 2012, 12(2), 190-197.

19. Y. Prawoto: 'Unified model for blister growth in coating degradation using weight function and diffusion concepts', Materials and Corrosion, 2013, 64(9), 794-800.

20. M. Nazir, Z. A. Khan, A. Saeed, and K. Stokes: 'A model for cathodic blister growth in coating degradation using mesomechanics approach', Materials and Corrosion, 2015.

21. M. Nazir, Z. A. Khan, and K. Stokes: 'A holistic mathematical modelling and simulation for cathodic delamination mechanism-a novel and an efficient approach', Journal of Adhesion Science and Technology, 2015, 29(22), 2475-2513.

22. M. Nazir, Z. A. Khan, A. Saeed, and K. Stokes: 'A predictive model for life assessment of automotive exhaust mufflers subject to internal corrosion failure due to exhaust gas condensation', Engineering Failure Analysis, 2016, 63, 43-60.

23. M. Nazir, Z. A. Khan, A. Saeed, and K. Stokes: 'Modeling the Effect of Residual and DiffusionInduced Stresses on Corrosion at the Interface of Coating and Substrate', Corrosion, 2015, 72(4), 500-517.

24. M. Nazir, Z. A. Khan, and K. Stokes: 'Analysing the coupled effects of compressive and diffusion induced stresses on the nucleation and propagation of circular coating blisters in the presence of micro-cracks', Engineering Failure Analysis, 2016, 70, 1-15.

25. A. Saeed, Khan, Z., and Montgomery, E.: 'Corrosion Damage Analysis and material Characterization of Sherman and Centaur - The Historic Military Tanks', Materials Performance and Characterization, February 6, 2013., 2(1), 30-44.

26. A. Saeed, Z. A. Khan, M. Hadfield, and S. Davies: 'Material characterization and real-time wear evaluation of pistons and cylinder liners of the tiger 131 military tank', Tribology Transactions, 2013, 56(4), 637-644.

27. M. H. Nazir, Z. A. Khan, A. Saeed, and K. Stokes: 'A model for cathodic blister growth in coating degradation using mesomechanics approach', Materials and Corrosion, 2015.

28. M. H. Nazir, Z. A. Khan, A. Saeed, and K. Stokes: 'Modeling the Effect of Residual and Diffusion-Induced Stresses on Corrosion at the Interface of Coating and Substrate', Corrosion, 2015, 72(4), 500-517.

29. A. Saeed, Z. Khan, M. Clark, N. Nel, and R. Smith: 'Non-destructive material characterisation and material loss evaluation in large historic military vehicles', Insight: Non-Destructive Testing and Condition Monitoring, 2011, 53(7), 382-386.

30. M. H. Nazir, Z. A. Khan, A. Saeed, and K. Stokes: 'A predictive model for life assessment of automotive exhaust mufflers subject to internal corrosion failure due to exhaust gas condensation', Engineering Failure Analysis, 2016, 63, 43-60.

31. A. Saeed: 'Sustainable methodology of conserving historic military vehicles', Bournemouth University, 2013.

32. A. Saeed, Z. A. Khan, and M. H. Nazir: 'Time dependent surface corrosion analysis and modelling of automotive steel under a simplistic model of variations in environmental parameters', Materials Chemistry and Physics, 2016, 178, 65-73.

33. M. H. Nazir, Z. A. Khan, and K. Stokes: 'A holistic mathematical modelling and simulation for cathodic delamination mechanism - a novel and an efficient approach', Journal of Adhesion Science and Technology, 2015, 1-39.

34. Z. A. Khan, M. Grover, and M. H. Nazir: 'The Implications of Wet and Dry Turning on the Surface Quality of EN8 Steel', in 'Transactions on Engineering Technologies', 413-423; 2015, Springer.

35. M. H. Nazir, Z. Khan, and K. Stokes: 'Modelling of metal-coating delamination incorporating variable environmental parameters', Journal of Adhesion Science and Technology, 2014, 29(5), 392-423.

36. M. Nazir, Z. Khan, A. Saeed, and K. Stokes: 'Modelling the Effect of Residual and Diffusion induced Stresses on Corrosion at the Interface of Coating and Substrate', Corrosion, 2015. 
37. M. H. Nazir, Z. A. Khan, and K. Stokes: 'Optimisation of Interface Roughness and Coating Thickness to Maximise Coating-Substrate Adhesion - A Failure Prediction and Reliability Assessment Modelling', Journal of Adhesion Science and Technology, 2015, 29(14), 14151445.

38. M. Nazir, Z. A. Khan, and K. Stokes: 'A unified mathematical modelling and simulation for cathodic blistering mechanism incorporating diffusion and fracture mechanics concepts', Journal of Adhesion Science and Technology, 2015, 29(12), 1200-1228.

39. M. H. Nazir, Z. A. Khan, and K. Stokes: 'Analysing the coupled effects of compressive and diffusion induced stresses on the nucleation and propagation of circular coating blisters in the presence of micro-cracks', Engineering Failure Analysis, 2016, 70, 1-15.

40. A. Saeed, Z. Khan, M. Clark, M. Nel, and R. Smith: 'Non-destructive material characterisation and material loss evaluation in large historic military vehicles', Insight-Non-Destructive Testing and Condition Monitoring, 2011, 53(7), 382-386.

41. M. H. Nazir, A. Saeed, and Z. Khan: 'A comprehensive predictive corrosion model incorporating varying environmental gas pollutants applied to wider steel applications', Materials Chemistry and Physics, 2017, 193, 19-34.

42. A. Saeed, Z. A. Khan, H. Nazir, M. Hadfield, and R. Smith: 'Research Impact Of Conserving Large Military Vehicles Through A Sustainable Methodology', International Journal of Heritage Architecture, 2017, 1(2), 267-274.

43. M. Nazir and Z. Khan: 'A review of theoretical analysis techniques for cracking and corrosive degradation of film-substrate systems', Engineering Failure Analysis, 2016.

44. R. Bajwa, Z. Khan, H. Nazir, V. Chacko, and A. Saeed: 'Wear and Friction Properties of Electrodeposited Ni-Based Coatings Subject to Nano-enhanced Lubricant and Composite Coating', Acta Metallurgica Sinica (English Letters), 2016, 29(10), 902-910.

45. Z. A. Khan, P. Pashaei, R. Bajwa, H. Nazir, and M. Cakmak: 'Fabrication and characterisation of electrodeposited and magnertron-sputtered thin films', International Journal of Computational Methods \& Experimental Measurements, 2015, 3(2), 165-174.

46. M. H. Nazir and Z. Khan: 'Maximising the interfacial toughness of thin coatings and substrate through optimisation of defined parameters', International Journal of Computational Methods and Experimental Measurements, 2015, 3(4), 316-328.

47. R. S. Bajwa, Z. Khan, V. Bakolas, and W. Braun: 'Effect of bath ionic strength on adhesion and tribological properties of pure nickel and Ni-based nanocomposite coatings', Journal of Adhesion Science and Technology, 2016, 30(6), 653-665.

48. R. S. Bajwa, Z. Khan, V. Bakolas, and W. Braun: 'Water-Lubricated Ni-Based Composite (NiAl2O3, Ni-SiC and $\mathrm{Ni}-\mathrm{ZrO} 2$ ) Thin Film Coatings for Industrial Applications', Acta Metallurgica Sinica (English Letters), 2015, 29(1), 8-16.

49. Anon; Available from: http://www.azom.com/article.aspx?ArticleID=6022.

50. E. Armelin, C. Ocampo, F. Liesa, J. I. Iribarren, X. Ramis, and C. Alemán: 'Study of epoxy and alkyd coatings modified with emeraldine base form of polyaniline', Progress in organic coatings, 2007, 58(4), 316-322.

51. C.-H. Hsueh: 'Modeling of elastic deformation of multilayers due to residual stresses and external bending', Journal of Applied physics, 2002, 91(12), 9652-9656.

52. X. Zhang, W. Shyy, and A. M. Sastry: 'Numerical simulation of intercalation-induced stress in Li-ion battery electrode particles', Journal of the Electrochemical Society, 2007, 154(10), A910-A916.

53. L. Mejlbro: 'The complete solution of Fick's second law of diffusion with time-dependent diffusion coefficient and surface concentration', Durability of Concrete in Saline Environment. Proceedings. P. Sandberg (Ed.) Lund, 1996, 127-158.

54. J. C.-M. Li: 'Physical chemistry of some microstructural phenomena', Metallurgical Transactions A, 1978, 9(10), 1353-1380.

55. S. Faulhaber, C. Mercer, M.-W. Moon, J. Hutchinson, and A. Evans: 'Buckling delamination in compressed multilayers on curved substrates with accompanying ridge cracks', Journal of the Mechanics and Physics of Solids, 2006, 54(5), 1004-1028.

56. J. Hutchinson, M. Thouless, and E. Liniger: 'Growth and configurational stability of circular, buckling-driven film delaminations', Acta metallurgica et materialia, 1992, 40(2), 295-308. 
57. S. R. Choi, J. W. Hutchinson, and A. Evans: 'Delamination of multilayer thermal barrier coatings', Mechanics of Materials, 1999, 31(7), 431-447.

58. M. Nazir, Z. A. Khan, and K. Stokes: 'Optimisation of interface roughness and coating thickness to maximise coating-substrate adhesion-a failure prediction and reliability assessment modelling', Journal of Adhesion Science and Technology, 2015, 29(14), 1415-1445.

59. T. Chuang and T. Nguyen: 'A non-osmotic blister growth model in coating systems', Damage and failure of interfaces. 1st International Conference. Proceedings, 1997, 203-209.

60. J. Martin, E. Embree, and W. Tsao: 'Non-osmotic, defect-controlled cathodic disbondment of a coating from a steel substrate', JCT, Journal of coatings technology, 1990, 62(790), 25-33.

61. M. Stratmann, A. Leng, W. Fürbeth, H. Streckel, H. Gehmecker, and K.-H. Große-Brinkhaus: 'The scanning Kelvin probe; a new technique for the in situ analysis of the delamination of organic coatings', Progress in Organic Coatings, 1996, 27(1), 261-267.

62. K.-t. Wan and K. Liao: 'Measuring mechanical properties of thin flexible films by a shaftloaded blister test', Thin Solid Films, 1999, 352(1), 167-172.

63. H. Jahnsen: 'Delamination of coatings', Handbook of Materials behavior models, 2001, 582586.

64. M. Kappes, G. Frankel, and N. Sridhar: 'Adhesion and adhesion degradation of a pressure sensitive tape on carbon steel', Progress in Organic Coatings, 2010, 69(1), 57-62.

65. M. Stratmann, R. Feser, and A. Leng: 'Corrosion protection by organic films', Electrochimica Acta, 1994, 39(8-9), 1207-1214.

66. K. N. Allahar, M. E. Orazem, and K. Ogle: 'Mathematical model for cathodic delamination using a porosity-pH relationship', Corrosion Science, 2007, 49(9), 3638-3658.

67. J. W. Hutchinson and Z. Suo: 'Mixed mode cracking in layered materials', Advances in applied mechanics, 1991, 29, 63-191. 